\title{
Exploring InTASC Standards and Principals from the Perspectives of Soka (Value-Creating) Education
}

\author{
Nai-Cheng Kuo ${ }^{1, *} \&$ Loretta Aniezue ${ }^{1}$ \\ ${ }^{1}$ Department of Teaching and Leading, Augusta University, 2500 Walton Way, Augusta, \\ Georgia 30904, USA \\ *Corresponding author: Department of Teaching and Leading, Augusta University, 2500 \\ Walton Way, Augusta, Georgia 30904, USA. E-mail: nkuo@ augusta.edu
}

Received: March 2, 2018 Accepted: March 16, 2018 Published: March 25, 2018

doi:10.5296/ije.v10i1.12754 URL: https://doi.org/10.5296/ije.v10i1.12754

\begin{abstract}
Value-creating education, developed by Tsunesaburo Makiguchi (1871-1944), Josei Toda (1900-1958), and Daisaku Ikeda (1928-present), is a relatively new educational philosophy based on compassion and love for humanity. Originating in Japan, this philosophy has gradually gained international attention through scholarly research, particularly in the United States (Sherman, 2016). In this paper, we discuss how value-creating education can maximize the use of the U.S. national teacher education standards, InTASC, across four categories: the learner and learning, content knowledge, instructional practice, and professional responsibility. By using value-creating education, we hope to cultivate teachers whose role is not merely to deliver knowledge but to nurture the next generation who will uphold the dignity of each individual's life.
\end{abstract}

Keywords: Value-creating education, teacher education, InTASC standards, humanistic education 


\section{Value-Creating Education}

The proud mission of those who have been able to receive education must be to serve, in seen and unseen ways, the lives of those who have not had this opportunity. At times, education may become a matter of titles and degrees, and the status and authority these confer. I am convinced, however, that education should be a vehicle to develop in one's character the noble spirit to embrace and augment the lives of others.

(Daisaku Ikeda, A New Humanism, 2010, p. 57)

Knowledge itself is neutral and can be used for good or bad. Therefore, teachers should have a philosophy that guides them to use knowledge, develop needed disposition, and practice their profession effectively. One of such philosophies is value-creating education. Value-creating education, developed by Tsunesaburo Makiguchi (1871-1944), Josei Toda (1900-1958), and Daisaku Ikeda (1928-present), is a relatively new educational philosophy based on compassion and love for humanity. Value-creating in Kanji (a Japanese writing system) is 創価 (Soka). “So (創)" means “create," and "ka (価)" means "value." Ikeda defines the meaning of value-creating education as "the capacity to find meaning, to enhance one's own existence, and to contribute to the well-being of others, under any circumstance" (Ikeda, 1996). In particular, value-creating education is to "(1) uphold the dignity of life; (2) respect individuality; (3) build bonds of lasting friendship; (4) oppose violence; and (5) lead a life based on both knowledge and wisdom" (Ikeda, 2003, p. 6). The ability to create value shapes one's personal life and impact positively on the lives of others and on society at large. Makiguchi argues that, like a physician prescribing the wrong medicine which can kill a person, miseducation is equally deadly to people and society (Ikeda, 2015).

Value-creating education "is concerned with expanding individual capacity or capability through an interactive process called human revolution, which functions to enhance one's well-being by seeking to create value in all aspects of one's life" (Sherman, 2016, p. 3). Ikeda (2017) argues that "a great human revolution in just a single individual will enable a change in the destiny of all humankind." It is like, "when you bow to a mirror, the reflected image bows back" (Gosho Zenshu, n.d., p. 769). Everything begins with the changes in one single individual. When teachers respect their students and develop a shared bond in a community, both of them are likely to continue deepening their knowledge, refining their character, and developing to their fullest. Ikeda affirms that:

...respect for humanity must be the basis of all institutions of learning....Any learning or search for truth not rooted in a concern for humanity is doomed to be abstract, futile, shallow, and fruitless. At present the world stands in danger once again of losing sight of this essential focus on humanity.

(Ikeda, 2015, p. 22)

Both expansive liberty and a high degree of self-discipline are important to carry on value-creating education. In Ikeda's view, this means that sharing ideas through dialogue, 
encompassing insight into the nature of things, advancing enthusiasm for learning, and collaboratively realizing the vision must be emphasized in educational institutions (Ikeda, 2015). Because the quality and the worth of a university are decided by the achievements of its students, teacher education programs must help preservice teachers build a foundation to dedicate their lives to their chosen paths and to work for the flourishing of the larger society (Boulding \& Ikeda, 2010). In the following sections, we discuss how value-creating education can maximize the use of teacher education standards. By using value-creating education to explore the U.S. national teacher education standards, InTASC, we hope to cultivate teachers whose role is not merely to deliver knowledge but to nurture the next generation who will uphold the dignity of each individual's life.

\section{InTASC Standards}

In teacher education, one important guide is the Interstate Teacher Assessment and Support Consortium (InTASC) Model Core Teaching Standards and Learning Progressions for Teachers 1.0: A Resource for Ongoing Teacher Development, developed by the Council of Chief State School Officers (CCSSO) in 2013. The purpose of the InTASC standards is to serve as a vision of the educational reform direction, to serve as a progress-based assessment for preand in-service teachers, and to clarify the provisions necessary to support teachers' opportunities to learn (CCSSO, 2013). There are ten standards that guide teachers' practice:1) learner development, 2) learning differences, 3) learning environments, 4) content knowledge, 5) application of content, 6) assessment, 7) planning for instruction, 8) instructional strategies, 9) professional learning and ethical practice, and 10) leadership and collaboration. These ten standards are further grouped into four categories: the learner and learning (Standards \#1, \#2, and \#3), content knowledge (Standards \#4 and \#5), instructional practice (Standards \#6, \#7, and \#8), and professional responsibility (Standards \#9 and \#10). Table 1 shows the categories of the standards and their descriptions.

Table 1. An overview of InTASC Standards

\begin{tabular}{|c|c|c|}
\hline Category & Standard & Description \\
\hline \multirow{3}{*}{$\begin{array}{l}\text { The Learner } \\
\text { and Learning }\end{array}$} & $\begin{array}{l}\text { Standard \#1: } \\
\text { Learner } \\
\text { Development }\end{array}$ & $\begin{array}{l}\text { The teacher understands how learners grow and develop, } \\
\text { recognizing that patterns of learning and development vary } \\
\text { individually within and across the cognitive, linguistic, social, } \\
\text { emotional, and physical areas, and designs and implements } \\
\text { developmentally appropriate and challenging learning } \\
\text { experiences. }\end{array}$ \\
\hline & $\begin{array}{l}\text { Standard \#2: } \\
\text { Learning } \\
\text { Differences }\end{array}$ & $\begin{array}{l}\text { The teacher uses understanding of individual differences and } \\
\text { diverse cultures and communities to ensure inclusive learning } \\
\text { environments that enable each learner to meet high standards. }\end{array}$ \\
\hline & $\begin{array}{l}\text { Standard \#3: } \\
\text { Learning } \\
\text { Environments }\end{array}$ & $\begin{array}{l}\text { The teacher works with others to create environments that support } \\
\text { individual and collaborative learning, and that encourage positive } \\
\text { social interaction, active engagement in learning, and } \\
\text { self-motivation. }\end{array}$ \\
\hline
\end{tabular}




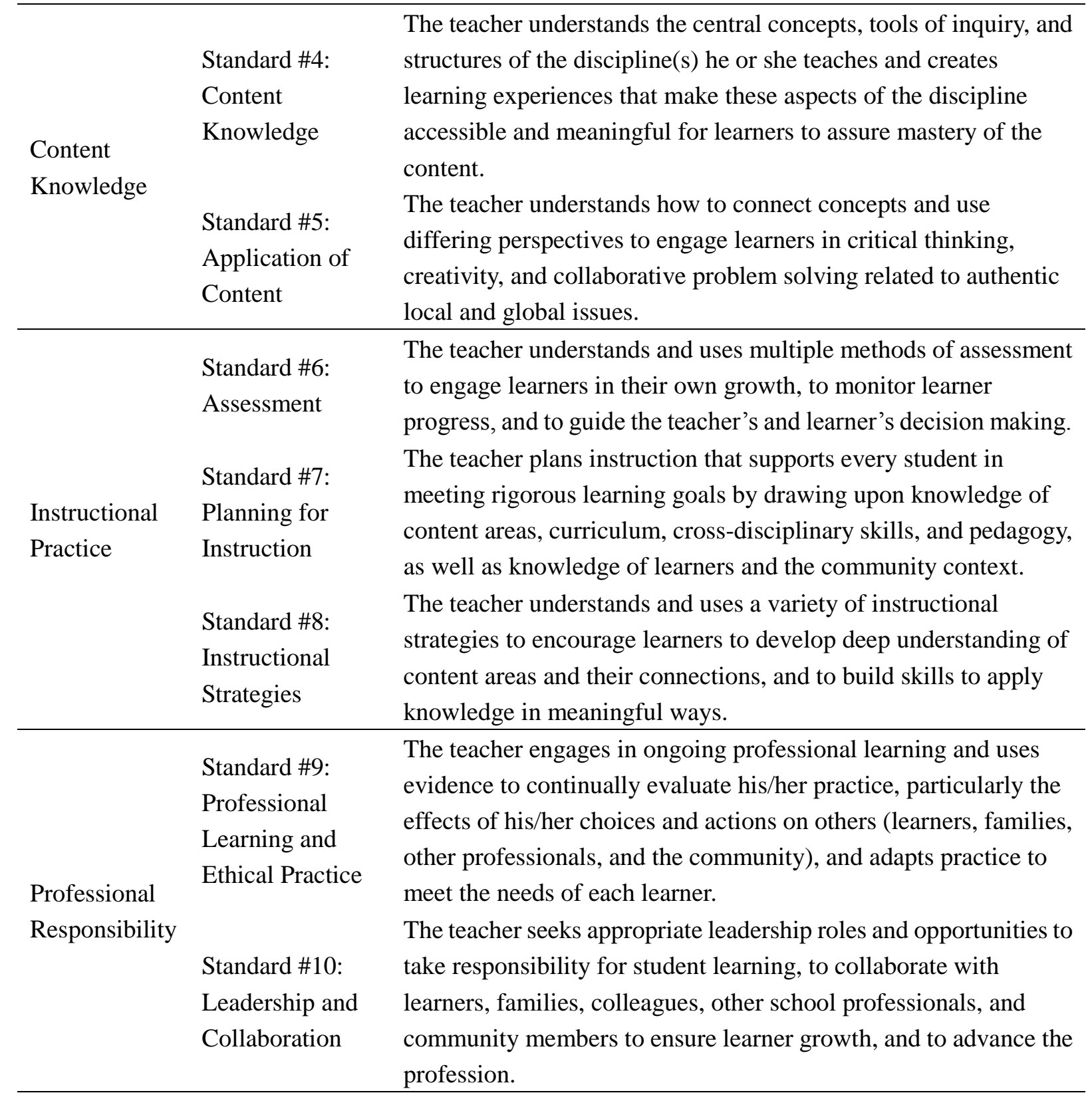

(CCSSO, 2013)

\subsection{The Learner and Learning - Creating Value through Respecting Human Dignity}

Standards \#1 and \#2 emphasize that teachers use knowledge to create instructional activities that will meet the needs of diverse students. There are different ways to view and interpret the standards due to teachers' varying perspectives, personalities and experiences. These differences in viewing and interpreting the standards may lead them to address the following questions differently: How can I make my students feel valued and help them value others? How can I help students use knowledge to create value in their own lives? How can students use knowledge to affect other people's lives positively? These questions are what teachers should find answers to for effective learning to take place and avoid education from being merely transmitting knowledge. 


\section{Mll Macrothink}

International Journal of Education

ISSN 1948-5476

2018, Vol. 10, No. 1

The ability of a teacher to ask and find answers to these questions is the essence of creating value and can have far reaching impact on the lives of the students. When a simple evaluation of the world today tells a gloomy story of using knowledge for fame, wealth, power, and wars, we see this gloominess being reflected in the behavior and attitude of our children. With so many tragedies happening in school, such as drug addiction, bullying, and shootings, this picture of gloominess has an urgent tone in it to find a remedy. We believe that the infusion of value-creating education into teacher education programs creates a way to reduce societal and educational problems. Ikeda argues that the world's interlocking problems are due to collective failure to respect human dignity. Therefore, "the human being is the point to which we must return and from which we must depart anew" (Ikeda, 1996, p. 25). By fostering the next generation with a right educational philosophy, a harmonious society will inevitably be achieved.

Standard \#3 requires teachers to recognize that their students are from diverse cultural backgrounds, often with exceptionalities. Having this awareness in mind, they should be prepared to develop creative instructional opportunities that are adapted to the cultural background of each student. These would be mere words if teachers are not exposed in any program that educates them about the cultural background of their students. For example, some people in America still believe the narrative that Africans live in jungles or that Africa is one country. One teacher from Nigeria shared that while teaching a lesson about Nigeria, her students described the living abodes of Nigerians as huts and trees, prior to showing them real-life photos of the different types of homes in the modern-day Nigeria. This calls for the need to update textbooks, content knowledge, and the ways that children gain information.

Value-creating education involves dialogue and global citizenship. There are a variety of ways to generate profound dialogue. For examples, teacher educators can begin dialogues with preservice teachers through nature, great books, and great works of arts. They can encourage dialogue among students, between students and faculty, and between students (Goulah \& Ito, 2012). Any pressing issues that affect teaching and learning locally and globally are also potential topics. Although there are some forms of written and oral communication taking place in colleges such as reflection papers or project presentations, dialogue of value-creating education is beyond mere paper or project presentations. Dialogue involves pursuing questions that spark each other's curiosity and long-and-deep thinking. Such dialogue promotes both a deeper understanding of each other, shapes dispositions, and ultimately puts people on the path as value-creating agents of change. Ikeda believes that this type of education is "far more than the mere transfer of information and knowledge; it enables us to rise above the confines of our parochial perspectives and passion" (Ikeda, 2008, p. 229). Dialogic interlocution makes teachers truly human and global citizens who are willing to foster respectful communication among all members of the learning community.

\subsection{Content Knowledge - Creating Value through Using Knowledge Properly}

Standard \#4 focuses on teachers' ability to make knowledge accessible and meaningful for students and Standard \#5 stresses students' use of content knowledge. The components that are repeatedly mentioned in these two standards are critical thinking, problem solving, 
performance skills, positive social interaction, active engagement and self-motivation. These are 21 st century skills that students are expected to develop for survival and successful living (CCSSO, 2013).

There are three critical issues here, the knowledge of content (what), the the instruction (how), and the purpose of the content (value). Many teachers may be conversant with the 'what' and the 'how' of teaching and learning, but they may not have a global view of educational value that they need to create in their instructional activities. Acknowledging this problem, Darling-Hammond (2001) stated that teachers should have the capacity to plan instruction that meets the needs of students and the demands of content knowledge. More importantly, the instruction should be purposeful and add up to essential knowledge. This means that there is a need for preservice teachers to be taught how to develop a global view of educational value, deepen essential knowledge of subject matters, and in return assist their students to appreciate the interconnectedness of all aspects of life. This perceptual paradigm shift in the teachers and their students is of the utmost importance if ever we will achieve the purpose of education - to create a better world for peace and the dignity of life. This is what Ikeda called the spirit of education (Goulah \& Ito 2012). When the spirit of education is sustained, content knowledge will be long-lived. Years down the line, students may not remember the specific content of a subject, but they will remember the value that they created with the content learned. They will remember how a teacher's caring and enthusiasm for education helped them find meaning in content knowledge, as well as how they used knowledge to understand themselves and others better .

Value-creating education can be conducted through different ways such as literature and arts, peace and humanistic education, as well as environmental and developmental education (Boulding \& Ikeda, 2010). In terms of literature and arts, Ikeda likens a great book to a great mentor. He believes that literature and arts can be excellent vehicles for exposing students to world views on various aspects of life and learning. They are culturally, historically, and educationally rich with insights one may never learn without appropriate guidance to relevant literatures and arts. One may argue that our schools expose students to a variety of literature and arts. However, simply exposing students to relevant literatures and arts and then asking them to write a review, a reflection, or take a test on it can neither truly develop students' passion for literature and arts, nor help them see the values therein. This type of practice, often seen in colleges and K-12 schools today, can only cultivate knowledge consumers, not knowledge creators. Students learn to create value when a dialogic platform is provided to help them critically test their beliefs and allow them to experience a paradigm shift. This embodies true learning and the spirit of education. Teacher educators should create opportunities to encourage preservice teachers to engage in dialogue that purposefully challenges perceptions, stereotypes, and assumptions they hold within themselves, or about other people who may not share their cultural, religious, or political beliefs. By doing so, it will propel them to appreciate the diversity, first within their immediate environment (locality) and then, in the world.

In respect of peace and humanistic education, education and civilization are supposed to broaden our views and lead us to a variety of options that take into consideration the differences of one's ability and culture. With the development of education and technology, 
Boulding and Ikeda (2010) emphasize the importance of peace and humanistic education to avoid knowledge from being misused. By learning the cruelty of violence through peace education and using knowledge with wisdom, we learn how to use knowledge in the right situation. Therefore, it is beneficial for teachers to be exposed to peace and humanistic education so that content knowledge will be channeled to a meaningful use.

Furthermore, severe weather, drought, desert encroachment, hunger, and diseases continue to ravage the world. Some nations are more affected than others. There is a clear line of the haves and the have-nots - with the haves spending billions of money to ensure that their people are shielded from environmental degradation and kept safe within the walls they build around them, while the have-nots struggle to even stay alive. In this realm of pursuing the lesser self (as opposed to the greater self), people often forget that "the world is an intricately interwoven web of infinite relations" (Ikeda, 2017) and that what affects one will affect the other because of the connectedness of life. Ikeda argues that environmental education must be taught to students so that they learn how to evaluate and analyze issues about ecological realities and use knowledge to find ways to protect the environment. By relating the value of content knowledge to environmental and developmental issues, value-creating education helps teachers and their students understand how the world is connected and how our actions and inactions affect that interconnectedness, positively or negatively.

\subsection{Instructional Practice - Creating Value through Respecting Individuality}

Standard \#6 emphasizes that teachers' ability of using formal and informal assessments that will lead to continuous intellectual, social, and physical development of students. Unfortunately, there are a number of assessment systems that do not inform instruction to prepare students for critical thinking and integrative skills. The use of such assessment systems belies the purpose of evaluating students' progress. When assessment systems focus mainly on whether or not students can recall facts, rather than equipping them with complex thinking and problem-solving skills, there is a fundamental imbalance of educational priority. In other words, the essence of education, which is to help students apply knowledge for the purpose of creating value for themselves, for others, and for the community is lost. Value-creating education helps teachers redirect the priorities of assessment and lay more emphases on cultivating students' capacity to live their lives connected to people and turn challenges into a source of creativity. In this way, learning becomes more meaningful for students.

Standard \#7 discusses planning instruction. It is in carrying out this activity that a teacher begins to unleash his or her creative ability to bring the different parts of teaching and learning together. The teacher uses his or her knowledge of students' different capabilities, strengths, weaknesses, learning styles, and personalities to differentiate instruction. A solid foundation of content knowledge is required, so are appropriate materials, strategies, classroom organization, and behavior management techniques. Value-creating education helps teachers see the value of knowledge in everyday life. When teachers help students understand how knowledge is connected with the real world, students are likely to use knowledge to create value for themselves and for others. Ikeda (2017) describes this power of creativity as a fire-like energy that transforms all kinds of knowledge and situations into dynamic new growth and 
advancement. Regarding a better classroom layout, Boulding and Ikeda (2010) suggest a consideration of listening circle, which allows students and teachers to see each other and understand both verbal and nonverbal communication. In this way, it encourages better participation and promotes inclusion.

Standard \#8 focuses on instructional strategies that require teachers to be aware of how they communicate with students and what they communicate to students. They must pay attention to their verbal and nonverbal communication as well as observe keenly those of their students. Teachers need to use different modes of communication to reach their students. This includes using technology, inquiry, interaction, and collaboration. Irrespective of how well instructional planning goes, if the teacher is not able to communicate the lesson effectively, then learning may not take place. If there is no learning, then there will be nothing to evaluate. This is why it is necessary for teachers to use effective communication skills while instructing students. It is important to note that the communicating choices people make, may be a reflection of who they are, their cultural background, and the philosophy guiding their belief system. This standard calls on teachers to reflect on the biases inherent in their cultural background and beliefs; and how these may affect their instructional practices. These biases may be seen especially in their verbal and nonverbal communication, in the voice tone and modulation, in the observation, interpretation, and response to students, and in the choice of communication media available to students during instructions. These biases can deeply affect students' learning.

Teachers must be conscious of how quickly children's keen senses can detect the apathy and cynicism in adults around them. When children make such detection during instruction, they may be deeply affected to the extent that further learning within that lesson will be totally lost. Students need to feel that they are valued and respected, and when they know this, trust between students and teachers will blossom, which will open their mind for deeper learning to take place and lead students to create value with the content of learning (Boulding \& Ikeda, 2010). Because a teacher's inner growth contributes to the happiness and educational advances of students, value-creating education helps improve teacher quality and quality of teaching.

\subsection{Professional Responsibility - Creating Value through Taking Action to Advance}

Standards \#9 and \#10 focus on teachers' ownership and responsibility for professional development such as ethical practice, communication, interaction, and partnerships. Stressing the importance of assuming responsibility, Ikeda (2017) believes that a teacher's true greatness can only manifest when he or she takes full responsibility for his or her personal growth and professional development.

Professional development is essential to teaching. Teachers who are constantly engaged in professional development will stay current and relevant to their profession. Moreover, professional development can help schools retain good teachers in the educational system. As a result of professional development, there has been a shift from providing teachers with pedagogical training to supporting teachers through collaboration and partnership programs. Numerous teacher education programs and K-12 schools now partner with each other to provide high quality induction and mentoring programs as well as clinical practice 
opportunities, workshops, conferences, and co-teaching. These offer a platform where all teachers can learn from each other to advance their teaching.

It is worth mentioning that professional development is not limited to a course, workshop, or conference. Ikeda (2010) argues that "our daily lives are filled with opportunities to develop ourselves and those around us. Each of our interactions with others - dialogue, exchange, and participation - is an invaluable chance to create value" (p. 58).In other words, despite the fact that teachers may have busy schedules and cannot attend many conferences or workshops, there are still opportunities for them to advance their knowledge and skills in daily lives such as having sincere and insightful dialogue with students, parents, colleagues, and people inside and outside the educational field. An example of promoting dialogic interaction is called Communities of Practice, which are based on two important premises. First, it is the day to day living of teaching experiences that embodies extensive knowledge acquired through critical dialogue and reflection with those who share similar experiences. Second, the plethora of knowledge accessible to teachers through communities of practices will increase professional knowledge and enhance student learning (Buysse, Sparkman, \& Wesley, 2016; Vescio, Ross, \& Adams, 2007). The interactions of members within communities of practice are influenced by mutual engagement, joint enterprise, and shared repertoire (Bertram, Culver, \& Gilbert, 2017). To build cultures of lifelong learning, teachers need to engage diverse students, parents, and educators in dialogue and be the heart of educational network.

\section{Conclusion}

Value-creating education is an educational philosophy that is important to shape teacher education standards positively. Ikeda (2015) states: "Education is what makes us fully human... and is the great enterprise of steadily and surely passing on the fullness of humanity from the past to the future" (p. 158). To pass the baton of enduring value of education on to the next generation, we need teachers who possess unwavering integrity, passion, and energy for their work. Teachers who are autocratic, arrogant, or disrespectful to their students create toxic situations in society. In contrast, teachers who dedicate themselves to creating value will enable students to surpass expectation and achieve beyond their capacity. Value-creating education encourages teachers to stand up with vision and resolve by connecting their work to the great flow of humanity. Teacher education programs can use value-creating education to raise preservice teachers' awareness that striving to meet the teacher education standards is more than just a pursuit of their personal career goals. Because nothing great can be achieved without encountering a good teacher in life, teachers can speed up the betterment and development of society when they possess the educational philosophy of value-creating education in their daily practice. The acquisition of such a philosophy will become an important determining factor between a great teacher of quality versus a mediocre one, an advocate versus a self-seeking person, a lifelong learner versus a short-sighted learner, and an agent of change versus a follower of change. 


\section{References}

Bertram, R., Culver, D.M., \& Gilbert, W. (2017). A university sport coach community of practice: Using a value creation framework to explore learning and social interactions. International Journal of Sports Science and Coaching, 12(3), 287-302. https://doi.org/10.1177/1747954117710503

Boulding, E., \& Ikeda, D. (2010). Into full flower: Making peace cultures happen. Dialogue Path Press, Cambridge, MA.

Buysse, V., \& Sparkman, K. L., \& Wesley, P. W. (2016). Communities of practice: Connecting what we know with what we do. Exceptional Children, 69(3), 263-277. https://doi.org/10.1177/001440290306900301

Council of Chief State School Officers (CCSSO). (2013). Interstate teacher assessment and support consortium (InTASC) model core teaching standards and learning progressions for teachers 1.0: A resource for ongoing teacher development. Washington, DC: Author.

Darling-Hammond, L. (2001). Thoughts on teacher preparation. Retrieved from https://www.edutopia.org/linda-darling-hammond-teacher-preparation

Gosho Zenshu (n.d.). The writings of Nichiren Daishonin. Retrieved from http://www.nichirenlibrary.org/en/wnd-2/Content/299.

Goulah, J., \& Ito, T. (2012). Daisaku Ikeda's curriculum of Soka education: Creating value through dialogue, global citizenship, and "human education" in the mentor-disciple relationship. Curriculum Inquiry, $42(1), \quad 56-79$. https://doi.org/10.1111/j.1467-873X.2011.00572.x

Ikeda, D. (1996). Thoughts on education for global citizenship. A speech delivered at Teachers College, Columbia University. Retrieved from http://www.daisakuikeda.org/sub/resources/works/lect/lect-08.html

Ikeda, D. (2003). The challenge of global empowerment: Education for a sustainable future. In Seeds of Change (p. 6). Tokyo: SGI.

Ikeda, D. (2008). My dear friends in America: Collected U.S. addresses, 1990-1996. Santa Monica, CA: World Tribune Press.

Ikeda, D. (2010). A new humanism. New York, NY: I.B. Tauris.

Ikeda, D. (2015). To the youthful pioneers of Soka: Lectures, essays, and poems on value-creating education. New Delhi, India: Eternal Ganges Press.

Ikeda, D. (2017). Words of wisdom by Daisaku Ikeda. Retrieved from http://www.ikedaquotes.org/

Sherman, P. D. (2016). Value creating education and the capability approach: A comparative analysis of Soka education's facility to promote well-being and social justice. Cogent Education. https://doi.org/10.1080/2331186X.2016.1138575 


\section{Macrothink}

Vescio, V., Ross, D., \& Adams, A. (2008). A review of research on the impact of professional learning communities on teaching practice and student learning. Teaching and Teacher Education, 24(1), 80-91. https://doi.org/10.1016/j.tate.2007.01.004

\section{Copyright Disclaimer}

Copyright for this article is retained by the author(s), with first publication rights granted to the journal.

This is an open-access article distributed under the terms and conditions of the Creative Commons Attribution license (http://creativecommons.org/licenses/by/3.0/). 